\title{
Taller-than-wide Thyroid Nodules With Microcalcifications Are at High Risk of Malignancy
}

\author{
KONSTANTINOS D. PAPAPOSTOLOU ${ }^{1}$, CATHERINE C. EVANGELOPOULOU ${ }^{1}$, IOANNIS A. IOANNIDIS ${ }^{1}$, \\ GEORGIA N. KASSI ${ }^{2,3}$, KONSTANTINOS S. MORFAS ${ }^{1}$, NIKOLAOS I. KARAMINAS ${ }^{1}$ and HELEN J. KARGA ${ }^{1}$ \\ ${ }^{1}$ Medical Diagnosis Group, Athens, Greece; \\ ${ }^{2}$ Department of Endocrinology, Metabolism and Diabetes Mellitus, \\ Nikea-Piraeus Agios Panteleimon General Hospital, Athens, Greece; \\ ${ }^{3}$ Endocrine Unit, Alexandra Hospital, Athens, Greece
}

\begin{abstract}
Background/aim: Previous studies have shown that there may be a diversity in the ultrasonographic (US) features discriminating a malignant from a benign thyroid nodule. We determined the reliability of the specific nodule shape in combination with other US features in predicting thyroid carcinomas. Patients and Methods: This was a retrospective single-center study investigating the association of the morphological characteristics of nodular goiters from preoperative US and color Doppler images with malignancy based on pathology. Results: We evaluated 254 thyroid nodules (malignant, $n=131$ ) from 205 patients. Multivariable logistic regression analysis showed that taller-than-wide shape [odds ratio $(O R)=25.3,95 \%$ confidence interval $(C I)=5.4-118.9 ; p<0.001]$, microcalcifications $(O R=4.9,95 \%$ $C I=2.5-9.5 ; p<0.001)$, hypoechogenicity $(O R=4.5 ; 95 \%$ $C I=2-10.3 ; p<0.001)$ and size $(O R=0.93 ; 95 \% C I=0.89$ $0.98 ; p=0.002)$ were independently associated with thyroid nodule malignancy. Additionally, we found a strong negative correlation between size and taller-than-wide shape of a thyroid nodule $(r=-0.41, p<0.001)$. Conclusion: Among the important indicators of thyroid malignancy, taller-than-wide nodules with microcalcifications are most likely to be malignant.
\end{abstract}

Thyroid nodules are common lesions and are being diagnosed with increasing frequency $(1,2)$. They are discovered either clinically or using sensitive imaging techniques (3). High-resolution ultrasonography (US) is a powerful tool for detecting thyroid lesions and identify

This article is freely accessible online.

Correspondence to: Helen J. Karga, MD, Ph.D., Medical Diagnosis Group, Aristidou and Gynosati, Koropi, 19004, Attiki, Greece. Tel: +30 2106628600, e-mail: hkarga@yahoo.gr

Key Words: Thyroid, nodule, shape, microcalcifications, malignancy. nodules even with a size of a few millimeters $(4,5)$. As the probability of a first diagnosed nodule being malignant is almost $7 \%$ (4), it is important for the clinician to be able to accurately distinguish between benign and malignant nodules in order to make the best clinical decision and minimize unnecessary surgical procedures.

Currently, US-guided fine-needle aspiration biopsy (FNAB) remains the gold standard within the diagnostic procedures in the workup of thyroid nodules. However, a significant number of cases give false-negative, nondiagnostic, indeterminate or suspicious results that are difficult for clinicians to assess (6-8). In this way, US and color Doppler standardized criteria are good diagnostic tools indicating position, size, margins, content, echogenicity, elasticity and vascular pattern of the nodule. For example, marked hypoechogenicity, microcalcifications, irregular margins, intranodular vascular images and low elasticity have been associated with malignancy (4, 9-13). Studies have recently shown that a round appearance or a taller-thanwide shape of the nodule can be a US pattern suggestive of malignancy and recently the shape of a nodule has been added to the imaging criteria for suspicious lesions $(12,14)$.

We aimed to investigate the association of the morphological characteristics of nodular goiters from preoperative US and color Doppler images with malignancy based on pathology.

\section{Patients and Methods}

Study design and patient population. This was a retrospective, single-center, cross-sectional study. We included patients with a nodular goiter who underwent routine preoperative US followed by total thyroidectomy between January 2012 and December 2017. The medical records of these patients were reviewed for demographics and thyroid nodule imaging and pathology results. All conventional and power color Doppler US of thyroid nodules were performed using a 6-12 MHz linear array transducer, logic 7 (KPI Healthcare Inc. Yorba Linda, CA, USA). The US findings were re-evaluated and interpreted by two radiologists with more than 20-year 
experience who were blinded to the final pathology results. The mean length of time between US and thyroidectomy was 2 months. Regarding multinodular lesions, only nodules more than $6 \mathrm{~mm}$ were finally evaluated. The investigated US features of the thyroid nodules included taller-than-wide shape (defined as an anteroposterior to transverse diameter ratio $\geq 1$ in the axial plane), hypoechogenicity, microcalcifications (defined as $\leq 1 \mathrm{~mm}$ ), irregular margins and intranodular vascularity. The study was approved by the Institutional Scientific Committee (00/16.10.2017).

Statistical analysis. Descriptive statistics are reported as the median and interquartile range (IQR) for continuous variables, and frequency and percentage for categorical variables. Continuous variables were compared using the Mann-Whitney $U$-test, while discrete variables were compared using the chi-square or Fisher's exact test, as appropriate. Univariate and multivariable logistic regression analyses were performed to determine the independent effects of sonographic variables associated with thyroid nodule malignancy using the Wald backward-selection method. Only statistically significant variables $(p<0.05)$ from univariable analysis were entered the multivariable analysis. A receiver operating characteristic curve analysis was performed to assess the diagnostic performance of the US features distinguishing benign from malignant thyroid nodules. Correlation between nodule size and taller-than-wide shape was also analyzed by bivariate linear regression analysis. A $p$-value of less than 0.05 was considered as statistically significant. All analyses were performed using SPSS version 23.0 (IBM, Armonk, NY, USA).

\section{Results}

We evaluated 254 nodules from 205 patients (female, $\mathrm{n}=176$ ) (Table I). Regarding the benign nodules $(n=123)$ the diagnosis included nodular goiter $(n=107)$, adenoma $(n=5)$ and Hashimoto's nodule ( $\mathrm{n}=11)$, while the great majority of malignant nodules were papillary carcinomas $(n=129)$ and only two were follicular carcinomas.

Univariate and multivariate logistic regression analyses are shown in Table II. Size [odds ratio $(\mathrm{OR})=0.93,95 \%$ confidence interval $(\mathrm{CI})=0.89-0.98 ; p=0.002]$, taller-thanwide shape $(\mathrm{OR}=25.3 ; 95 \% \quad \mathrm{CI}=5.4-118.9 ; \quad p<0.001)$, microcalcifications $(\mathrm{OR}=4.9,95 \% \mathrm{CI}=2.5-9.5 ; p<0.001)$, hypoechogenicity $(\mathrm{OR}=4.5,95 \% \mathrm{CI}=2-10.3 ; p<0.001)$ of thyroid nodules were the only variables independently associated with thyroid malignancy (Table II). Taller-thanwide shape compared to the other US features demonstrated the highest specificity, at $98 \%$, for distinguishing malignant from benign thyroid nodules (Table III), reaching 100\% when combined with the presence of microcalcifications (data not shown). Moreover, we found a strong negative linear correlation between the taller-than-wide shape and the size of the nodules, $\mathrm{r}=-0.41, p<0.001$ (Figure 1).

\section{Discussion}

This study indicates that in a clinical sample of patients with nodular goiters referred to our center, the majority of nodules
Table I. Baseline characteristics of the study cohort.

\begin{tabular}{lcccc}
\hline $\begin{array}{l}\text { Baseline } \\
\text { characteristics }\end{array}$ & All & $\begin{array}{c}\text { Benign } \\
\text { thyroid } \\
\text { nodules }\end{array}$ & $\begin{array}{c}\text { Malignant } \\
\text { thyroid } \\
\text { nodules }\end{array}$ & $p$-Value \\
\hline Total, n & 205 & 85 & 120 & \\
$\begin{array}{l}\text { Female, n (\%) } \\
\text { Age, median }\end{array}$ & $176(86 \%)$ & $72(85 \%)$ & $104(87 \%)$ & 0.690 \\
$\begin{array}{l}\text { (IQR), years } \\
\text { Single } \\
\text { nodule, n }(\%)\end{array}$ & $158(77 \%)$ & $63(74 \%)$ & $95(79 \%)$ & 0.405 \\
\hline
\end{tabular}

IQR: Interquartile range.

with papillary carcinomas had a taller-than-wide shape, significantly higher than that of benign. Additionally, a significant number of carcinomas had micro-calcifications, but the most important finding was the coexistence of microcalcifications in nodules with a taller-than-wide shape which represented the one third of our malignant nodules. None of the benign nodules with taller-than-wide shape had microcalcifications, increasing the specificity to $100 \%$.

From the results of multiple studies is suggested that none individual US feature can accurately discriminate a malignant nodule and US alone cannot be used for the decision of surgical intervention (15-17). Furthermore, the Thyroid Imaging Reporting and Data System, which is applied primarily to exclude a thyroid malignant lesion, until now is not widely accepted to allow the clinicians for a proper therapeutic decision (18). Again, many studies evaluated the US findings by comparison with the cytological results after FNAB (16-18) but several factors can affect the diagnostic accuracy of FNAB, such as the experience of physicians in its performance, sampling error, non-diagnostic reports or cytological atypia of undetermined significance (19).

In several studies, the main suspicious features indicating thyroid malignancy were found to have different diagnostic power among different cohorts, as demonstrated from the ORs in multivariate analysis $(17,20,21)$. For example, Liu et al. (20) and Moon et al. (21) found that microcalcifications were a stronger predictor of papillary carcinoma among other US features, following by nodule shape. Additionally, Capelli et al. reported an OR for malignant nodules of 8.6 for those with taller-than-wide shape (17).

In the current work, hypoechoic nodules, nodules with illdefined margins, or those with intranodular vascularity had a high OR for malignancy but the highest OR was found for nodules with macrocalcifications and those nodules with taller-than-wide shape. In our cases, taller-than-wide shape, hypoechogenecity and microcalcifications were the most important factors predicting malignancy in multivariate 
Papapostolou et al: Thyroid Nodules and Malignancy

Table II. Univariate and multivariate logistic regression analysis of ultrasonographic features of thyroid nodules associated with malignancy.

\begin{tabular}{|c|c|c|c|c|c|c|}
\hline \multirow[b]{2}{*}{ Variable } & \multicolumn{3}{|c|}{ Univariable analysis } & \multicolumn{3}{|c|}{ Multivariable analysis } \\
\hline & OR & $95 \% \mathrm{CI}$ & $p$-Value & OR & $95 \% \mathrm{CI}$ & $p$-Value \\
\hline Size & 0.89 & $0.86-0.93$ & $<0.001$ & 0.93 & $0.89-0.98$ & 0.002 \\
\hline Microcalcifications & 6.7 & $3.9-11.6$ & $<0.001$ & 4.9 & $2.5-9.5$ & $<0.001$ \\
\hline Intranodular vascularity & 1.8 & $1-3.3$ & 0.042 & & & \\
\hline Ill-defined margins & 3.4 & $1.9-6.1$ & $<0.001$ & & & \\
\hline Taller-than-wide shape & 33.8 & $8-143$ & $<0.001$ & 25.3 & $5.4-118.9$ & $<0.001$ \\
\hline Hypoechogenic & 6.5 & $3.3-12.9$ & $<0.001$ & 4.5 & $2-10.3$ & $<0.001$ \\
\hline
\end{tabular}

OR: Odds ratio; CI: confidence interval.

Table III. Diagnostic performance of ultrasonographic (US) features distinguishing malignant from benign thyroid nodules.

\begin{tabular}{lcccccccc}
\hline US feature & AUC & $95 \% \mathrm{CI}$ & $p$-Value & SN $(\%)$ & SP $(\%)$ & PPV (\%) & NPV (\%) & Accuracy (\%) \\
\hline Microcalcifications & 0.721 & $0.657-0.785$ & $<0.001$ & 70 & 74 & 74 & 70 & 72 \\
Taller-than-wide shape & 0.671 & $0.605-0.738$ & $<0.001$ & 36 & 98 & 95 & 59 & 66 \\
Hypo-echogenicity & 0.657 & $0.590-0.725$ & $<0.001$ & 41 & 90 & 82 & 59 & 65 \\
Size & 0.754 & $0.696-0.813$ & $<0.001$ & & & & & \\
\hline
\end{tabular}

AUC: Area under the receiver operating characteristics curve; CI: confidence interval; PPV: positive predictive value; NPV: negative predictive value; SN: sensitivity; SP: specificity.

regression analysis. Taller-than-wide nodule shape had a much higher OR than microcalcifications (33.8 vs. 6.7), whereas intranodular vascularity or ill-defined margins were not enough to determine a high risk of malignancy, as previously described (22). This was confirmed by the AUCs which are also used to evaluate the diagnostic accuracy. The AUCs of shape, microcalcifications and the combination of both were $0.671,0.721$ and 0.649 respectively, demonstrating relatively good accuracy, showing the combination also to be as useful as the shape or the presence of microcalcifications alone in predicting malignancy. It is known that the coexistence of two or more highly suspicious US criteria greatly increases the potential risk for nodules being malignant $(17,23)$. In our work, the combination of microcalcifications and taller-than-wide shape was an independent predictor of malignancy and although the sensitivity was only approximately $30 \%$, the specificity was $100 \%$, since none of the benign nodules with taller-than-wide shape were found to have microcalcifications. This means that the coexistence of microcalcifications in taller-than-wide nodules provides strong evidence of malignancy, although the absence of this profile cannot exclude malignancy.

It should also be pointed out that marked hypoechogenecity was common in our malignant nodules, with an OR of 6.5, higher than previously reported (24) indicating an increased risk of malignancy, whereas intranodular vascularity or illdefined margins were adequate for determining a high risk of malignancy. When hypoechogenecity was evaluated in combination with microcalcifications and with the shape, our results showed no improvement of sensitivity or higher AUC (data not shown). In our study, nodules with taller-than-wide shape or shape combined with microcalcifications were the best predictors of malignancy.

It should also be noted that the size of malignant nodules was significantly lower than that of benign ones, reflecting the strong negative correlation between the nodule size and taller-than-wide shape. This might mean that smaller nodules with taller-than-wide shape are more often malignant than larger ones. Previous studies have examined the correlation between malignancy and nodule size $(25,26)$. These studies included large nodules $(>3 \mathrm{~cm})$ and size correlated with the FNAB results and other US findings but not with the shape as evaluated in our study. Hammad et al. proposed a cut-off point of $6 \mathrm{~cm}$ where the incidence of carcinoma decreases with increasing size of thyroid nodules (26). The anteroposterior nodule diameter might be suitable for assessing thyroid malignancy in microcarcinomas, with a critical value $>0.7 \mathrm{~cm} \mathrm{(12).}$

In our study, one limitation included a lack of a large number of nodules more than $4 \mathrm{~cm}$ in size. The explanation for this is that clinicians often recommend thyroid US to their patients and thyroid cancer is increasingly discovered at an early stage (27). A strength of our study is that there were final pathological results for all nodules after 


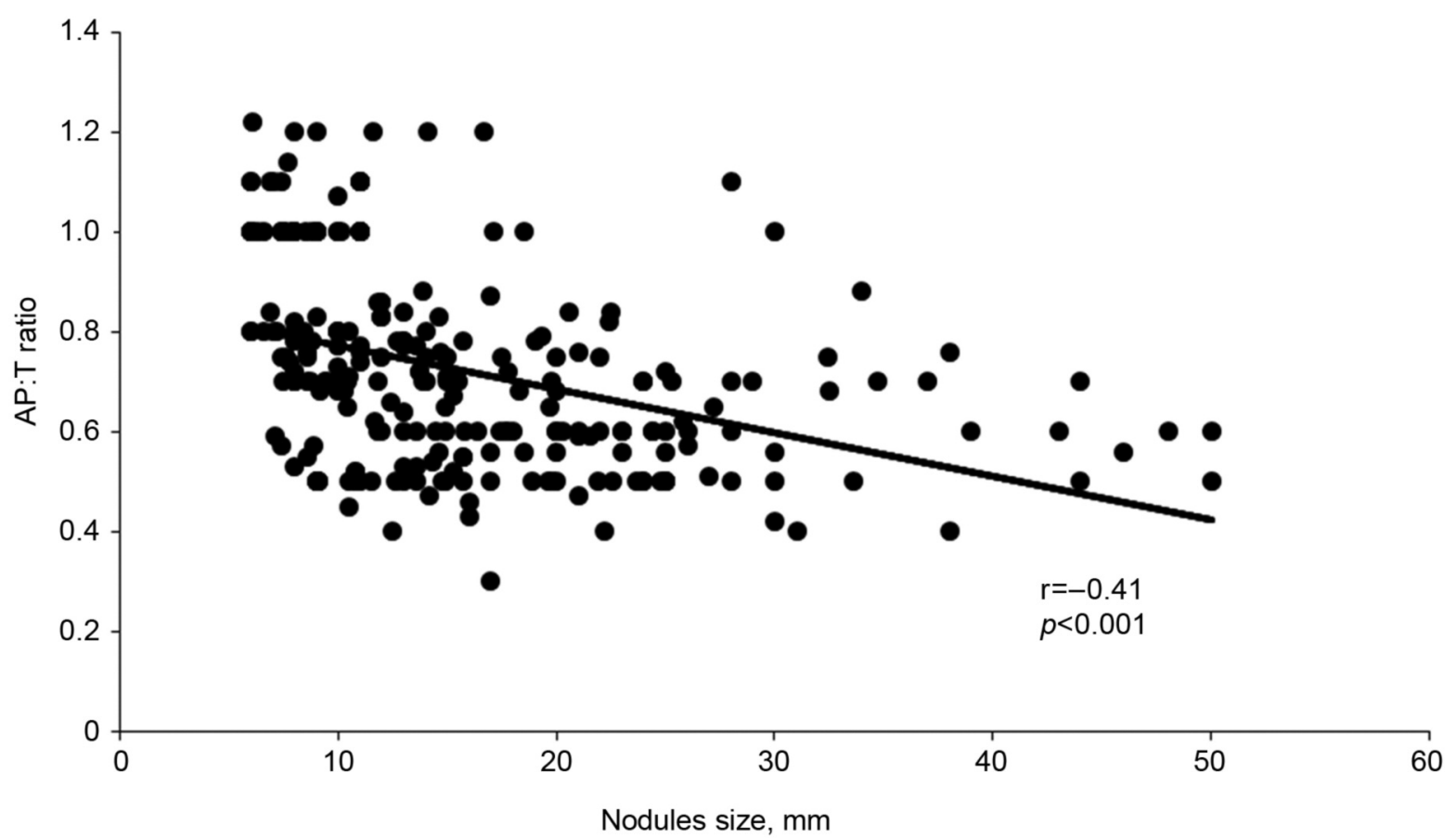

Figure 1. Correlation between thyroid nodule size and taller-than-wide shape [anteroposterior to transverse (AP:T) diameter ratio].

thyroidectomy and there was no selection bias since all patients who had undergone operations were included, without exception, and this explains how the potential malignancy rate was higher in comparison with the nonoperated on nodules. On the other hand, the main limitation of the study was the relatively small number of nodules included and that it was a single-center study.

In conclusion, the current study emphasizes that among the important indicators of thyroid malignancy, taller-than-wide nodules with microcalcifications are most likely to be malignant and surgical treatment should be considered for these patients. The strong negative correlation between thyroid nodule size and the taller-than-wide shape (potential malignancy) needs additional studies including more larger nodules.

\section{Conflicts of Interest}

The Authors declare no conflicts of interest in regard to this study.

\section{Authors' Contributions}

K.D.P: study concept and design, data analysis and interpretation, statistical analysis and article writing; H.J.K: study concept design, data analysis and interpretation and critical revision of the article; C.C.E., I.A.I., K.S.M., N.I.K.: data acquisition and interpretation and critical revision of the article; G.N.K.: statistical analysis and critical revision of the article.

\section{References}

1 Moon JH, Hyun MK, Lee JY, Shim JI, Kim TH, Choi HS, Ahn HY, Kim KW, Park DJ, Park YJ and Yi KH: Prevalence of thyroid nodules and their associated clinical parameters: a largescale, multicenter-based health checkup study. Korean J Intern Med 32: 536-547, 2017. PMID: 28859466. DOI: 10.3904/kjim. 2015.273

2 Kilfoy BA, Zheng T, Holford TR, Han X, Ward MH, Sjodin A, Zhang Y, Bai Y, Zhu C, Guo GL, Rothman N and Zhang Y: International patterns and trends in thyroid cancer incidence 1973-2002. Cancer Causes Control 20: 525-531, 2009. PMID: 19016336. DOI: 10.1007/s10552-008-9260-4

3 Marqusee E, Benson CB, Frater MC, Doubilet PM, Larsen PR, Cibas ES and Mandel SJ: Usefulness of ultrasonography in the management of nodular thyroid disease. Ann Intern Med 133: 696-700, 2000. PMID: 11074902. DOI: 10.7326/0003-4819-1339-200011070-00011

4 Rago T, Vitti P, Chiovato L, Mazzeo S, De Liperi A, Miccoli P, Viacava P, Bogazzi F, Martino E and Pinchera A: Role of conventional ultrasonography and color flow-doppler sonography in predicting malignancy in "cold" thyroid nodules. Eur J Endocrinol 138: 41-46, 1998. PMID: 9461314. DOI: 10.1530/eje. 0.1380041

5 Frates MC, Benson CB, Doubilet PM, Kunreuther E, Contreras M, Cibas ES, Orcutt J, Moore FD Jr, Larsen PR, Marqusee E and Alexander EK: Prevalence and distribution of carcinoma in patients with solitary and multiple thyroid nodules on sonography. J Clin Endocrinol Metab 91: 3411-1417, 2006. PMID: 16835280. DOI: 10.1210/jc.2006-0690 
6 Paajanen I, Metso S, Jaatinen P, Kholová I: Thyroid FNA diagnosis in a real-life setting: Experience of the implementation of the Bethesda system in Finland. Cytopathology 29: 189-195, 2017. PMID: 29251367. DOI: $10.1111 /$ cyt.12513

7 Yeh MW, Demicran O, Ituarte P and Clark OH: False-negative fine needle aspiration cytology results delay treatment and adversely affect outcome in patients with thyroid carcinoma. Thyroid 14: 207-215, 2004. PMID: 15072703. DOI: 10.1089/ 105072504773297885

8 Le AR, Thompson GW and Hoyt BJ: Thyroid fine-needle aspiration biopsy: an evaluation of its utility in a community setting. J Otolarynol Head Neck Surg 44: 12, 2015. PMID: 25890284. DOI: 10.1186/s40463-015-0063-9

9 Wang Y, Nie F, Liu T, Yang D, Li Q, Li J and Song A: Revised value of contrast-enhanced ultrasound for solid hypo-echoic thyroid nodules graded with thyroid imaging reporting and data system. Ultrasound Med Biol 44: 930-940, 2018. PMID: 29472113. DOI: 10.1016/j.ultrasmedbio.2017.12.018

10 Park SH, Kim SJ, Kim EK Kim MJ, Son EJ and Kwak JY: Interobserver agreement in assessing the sonographic and elastographic features of malignant thyroid nodules. Am J Roentgenol 193: 416-423, 2009. PMID: 19843721. DOI: 10.2214/AJR.09.2541

11 Moon HJ, Kwak JY, Kim MJ, Son EJ and Kim EK: Can vascularity at power Doppler US help predict thyroid malignancy? Radiology 255: 260-269, 2010. PMID: 20308462 DOI: 10.1148/radiol.09091284

12 Huang K, Gao N, Zhai Q, Bian D, Wang D and Wang X: The anteroposterior diameter of nodules in the risk assessment of papillary thyroid microcarcinoma. Medicine 97: e9712, 2018. PMID: 29517693. DOI: 10.1097/MD.0000000000009712

13 Rago T, Scutari M, Loiacono V, Santini F, Tonacchera M, Torregrossa L, Giannini R, Borrelli N, Proietti A, Basolo F, Miccoli P, Piaggi P, Latrofa F and Vitti P: Low elasticity of thyroid nodules on ultrasound elastography is correlated with malignancy, degree of fibrosis and high expression of galectin3 and fibronectin-1. Thyroid 27: 103-110, 2017. PMID: 27809694. DOI: 10.1089/thy.2016.0341

14 Liu J, Zheng D, Liq Q, Tang X, Luo Z, Yuan Z, Gao L and Zhao $\mathrm{J}$ : A predictive model of thyroid malignancy using clinical, biochemical and sonographic parameters for patients in a multicenter setting. BMC Endocr Disord 18: 17, 2018. PMID: 29514621. DOI: 10.1186/s12902-018-0241-7

15 Na DG, Baek JH, Sung JY, Kim JH, Kim JK, Choi YJ and Seo $\mathrm{H}$ : Thyroid reporting and data system risk stratification of thyroid nodules: Categorization based on solidity and echogenicity. Thyroid 4: 562-572, 2016. PMID: 26756476. DOI: 10.1089 /thy. 2015.0460

16 Eun NL, Yoo MR, Gweon HM, Park AY, Kim JA, Youk JH, Moon HJ, Chang HS and Son EJ: Thyroid nodules with nondiagnostic results on repeat fine-needle aspiration biopsy: which nodules should be considered for repeat biopsy or surgery rather than follow-up? Ultrasonography 35: 234-243, 2016. PMID: 27068131. DOI: 10.14366/usg.15079

17 Cappelli C, Castellano M, Pirola I, Gandossi E, De Martino E, Cumetti D, Agosti B and Rosei EA: Thyroid nodule shape suggests malignancy. Eur J Endocrinol 155: 27-31, 2006. PMID: 16793946. DOI: 10.1530/eje.1.02177
18 Peccin S, de Castsro JA, Furlanetto TW, Furtado AP, Brasil BA and Czepielewski MA: Ultrasonography: is it useful in the diagnosis in thyroid nodules? J Endocrinol Invest 25: 39-43, 2002. PMID: 11885575. DOI: 10.1007/bf03343959

19 Kim HG, Moon HJ, Kwak JY and Kim EK: Diagnostic accuracy of the ultrasonographic features for subcentimeter thyroid nodules suggested by the revised American Thyroid Association guidelines. Thyroid 23: 1583-1589, 2013. PMID: 23701365. DOI: $10.1089 /$ thy.2012.0586

20 Liu Y, Wu H, Zhou Q, Gou J, Xu J, Liu Y and Chen Q: Diagnostic value of conventional ultrasound combined with contrast-enhanced ultrasonography in thyroid imaging reporting and data system (TI-RADS) 3 and 4 thyroid micronodules. Med Sci Monit 22: 3086-3094, 2016. PMID: 27580248. DOI: $10.12659 / \mathrm{msm} .897011$

21 Moon WJ, Jung SL, Lee JH, Na DG, Baek JH, Lee YH, Kim J, Kim HS, Byun JS, Lee DH Benign and malignant thyroid nodules: US differentiation -multicenter retrospective study. Radiology 247: 762-770, 2008. PMID: 18403624. DOI: 10.1148/radiol.2473070944

22 Remonti LR, Kramer CK, Leitao CB, Leitão CB, Pinto LC and Gross JL: Thyroid ultrsound features and risk of carcinoma: A systematic review and meta-analysis of observational studies. Thyroid 5: 538-550, 2015. PMID: 25747526. DOI: 10.1089/ thy.2014.0353

23 Papini E, Guglielmi R, Bianchini A, Crescenzi A, Taccogna S, Nardi F, Panunzi C, Rinaldi R, Toscano V and Pacella CM: Risk of malignancy in nonpalpable thyroid nodules: predictive value of ultrasound and color -Doppler features. J Clin Endocrinol Metab 87: 1941-1946, 2002. PMID: 11994321. DOI: 10.1210/ jcem.87.5.8504

24 Xue E, Zheng M, Zhang S, Huang L, Qian Q and Huang Y: Ultrasonography-based classification and reporting system for the malignant risk of thyroid nodules. J Nippon Med Sch. 84: 118-124, 2017. PMID: 28724845. DOI: $10.1272 /$ jnms.84.118

25 Kamran SC, Marqusee E, Kim MI, Frates MC, Ritner J, Peters H, Benson CB, Doubilet PM, Cibas ES, Barletta J, Cho N, Gawande A, Ruan D, Moore FD Jr., Pou K, Larsen PR and Alexander EK: Thyroid nodules size and prediction of cancer. J Clin Endocrinol Metab 98: 564-570, 2013. PMID: 23275525. DOI: $10.1210 /$ jc.2012-2968

26 Hammad AY, Noureldine SI, Hu T, Ibrahim Y, Masoodi HM and Kandil E: A meta-analysis examining the independent association between thyroid nodule size and malignancy. Gland Surg 5: 312-317, 2016. PMID: 27294039. DOI: 10.21037/ gs.2015.11.05

27 Karga H, Mavroudis K, Giagourta I, Triantaphyllopoulou M, Ktena V, Kassi G, Veloutsou H and Papapetrou P: Changes in TNM stage reoperation and 131-I ablation rate during the use of newer methods for the preoperative diagnosis of differentiated thyroid carcinoma. Clin Endocrinol 76: 289-296, 2012. PMID: 21848910. DOI: 10.1111/j.1365-2265.2011.04199.x

Received March 14, 2020

Revised April 3, 2020

Accepted April 8, 2020 